Published in final edited form as:

J Neurol. 2011 September ; 258(9): 1676-1682. doi:10.1007/s00415-011-6001-5.

\title{
Genetic predictors of 25-hydroxyvitamin D levels and risk of multiple sclerosis
}

\author{
Kelly Claire Simon, \\ Department of Nutrition, Harvard School of Public Health, 677 Huntington Ave, Building 2, 3rd \\ floor, Boston, MA 02115, USA ksimon@hsph.harvard.edu
}

K. L. Munger,

Department of Nutrition, Harvard School of Public Health, 677 Huntington Ave, Building 2, 3rd floor, Boston, MA 02115, USA

P. Kraft,

Program in Molecular and Genetic Epidemiology, Epidemiology Department, Harvard School of Public Health, Boston, MA, USA

D. J. Hunter,

Program in Molecular and Genetic Epidemiology, Epidemiology Department, Harvard School of Public Health, Boston, MA, USA

Channing Laboratory, Department of Medicine, Brigham and Women's Hospital and Harvard Medical School, Boston, MA, USA

P. L. De Jager, and

Program in Translational NeuroPsychiatric Genomics, Department of Neurology, Brigham and Women's Hospital, Boston, MA, USA

Harvard Medical School, Boston, MA, USA

Program in Medical and Population Genetics, Broad Institute of Harvard University and Massachusetts Institute of Technology, Cambridge, MA, USA

\author{
A. Ascherio \\ Department of Nutrition, Harvard School of Public Health, 677 Huntington Ave, Building 2, 3rd \\ floor, Boston, MA 02115, USA \\ Channing Laboratory, Department of Medicine, Brigham and Women's Hospital and Harvard \\ Medical School, Boston, MA, USA \\ Department of Epidemiology, Harvard School of Public Health, Boston, MA, USA
}

\section{Abstract}

Risk of multiple sclerosis (MS) decreases with increasing plasma levels of 25-hydroxyvitamin D $[25(\mathrm{OH}) \mathrm{D}]$. If this association reflected a protective effect of vitamin D, MS risk should be lower among individuals carrying genetic variants that predict high $25(\mathrm{OH}) \mathrm{D}$ levels. The aim of the study was to determine whether individuals with genotypes predicting higher 25(OH)D levels have decreased MS risk. Logistic regression was used to assess the association between single nucleotide polymorphisms (SNPs) associated with 25(OH)D levels and MS risk in 1,655 cases and 6,349 controls. Analyses were further stratified by $H L A-D R 15$ status, assessed by genotyping a single SNP strongly correlated with the $H L A D R B 1 * 1501$ risk haplotype, and complemented by 
considering a SNP near $C Y P 27 B 1$. SNPs in $G C$ were predictors of 25(OH)D levels, but not MS risk, in either $H L A-D R 15$ negative or $H L A-D R 15$ positive individuals. In contrast, there was a suggestion of a difference in the effect of a $C Y P 2 R 1$ allele dependent on $H L A-D R 15$ genotype. The ' $A$ ' allele of $C Y P 2 R 1$ rs 10741657 was associated with increased $25(\mathrm{OH}) \mathrm{D}$ levels and a nonsignificant reduced MS risk among $H L A-D R 15$ negative (OR $=0.89,95 \%$ CI: $0.79,1.01)$ that was not apparent in $H L A-D R 15$ positive individuals. The ' $C$ allele of $C Y P 27 B 1$ rs703842 was inversely associated with MS risk; this association appeared stronger among $H L A-D R 15$ negative (OR $=0.79,95 \%$ CI: $0.69,0.90)$ compared to $H L A-D R 15$ positive individuals (OR $=0.91,95 \%$ CI: $0.80,1.04)$. This preliminary finding suggests the possibility that the putative beneficial effect of vitamin D on MS risk maybe attenuated in individuals carrying the $H L A-D R 15 \mathrm{MS}$ risk allele.

\section{Keywords}

Multiple sclerosis; Genetics; HLA-DR15; Vitamin D; 25-hydroxyvitamin D

\section{Introduction}

In longitudinal studies, both higher vitamin D intake [1] and high serum levels of 25hydroxyvitamin vitamin D (25(OH)D) [2], which is a good biomarker of availability of vitamin $\mathrm{D}$ to tissues, have been found to be inversely related to MS risk. These observations, and experimental evidence that vitamin D may modulate autoimmune responses [3], support the hypothesis that high vitamin D levels may protect against MS [4]. On the other hand, a conserved vitamin D responsive element (VDRE) was recently found to be present in the promoter region of the $H L A D R B 1 * 1501 \mathrm{MS}$ risk haplotype (HLA-DR15) [5]. This finding suggests that the effect of vitamin D on MS risk may be dependent on an individual's $H L A$ DR15 status.

Ideally, the relation between 25(OH)D levels and MS risk should be studied directly in large longitudinal studies. These studies, however, are difficult to conduct, because they involve the collection of serial blood samples from large numbers of healthy individuals. An alternative approach, sometimes referred to as 'Mendelian randomization' [6], involves using genetic factors that predict the exposure of interest as a proxy for the exposure itself. If vitamin $\mathrm{D}$ had a protective effect, individuals with geno-types associated with higher $25(\mathrm{OH}) \mathrm{D}$ would be expected to have a reduced MS risk, unless the same genotypes also increase MS risk through independent mechanisms. Although reliance on the latter assumption is an important limitation, this may be in part offset by the advantage of having a measure of exposure that does not vary in time, is easy to measure, and may reflect long term differences between individuals from birth up to the time of disease onset. The latter is particularly important in investigations of vitamin D levels, which vary considerably with age and season, so that levels at a single point in time may have only a modest effect on MS risk.

We, therefore, undertook to examine the relationship between genetic predictors of $25(\mathrm{OH}) \mathrm{D}$ levels, identified by conducting a genome-wide association study of $25(\mathrm{OH}) \mathrm{D}$ levels, and MS risk in the presence or absence of $H L A-D R 15$.

\section{Methods}

\section{Human subjects}

This work was approved by the appropriate ethics committee. 


\section{Identification of genetic predictors of 25(OH)D}

Study population-The study population included 872 women (436 women with breast cancer and 436 healthy control women) enrolled in the Nurses' Health Study (NHS). These women were selected because they had participated in a genome-wide association study (GWAS), the Cancer Genetic Markers of Susceptibility (CGEMS) study [7], and in a study of breast cancer risk that involved measurement of plasma levels of $25(\mathrm{OH}) \mathrm{D}$ [8]. All participants were also included in a concurrent collaboration with investigators at the NCI to perform a meta-analysis of genome-wide association with 25(OH)D levels [9].

Methods-Genotyping in the CGEMS study was performed using the Illumina HumanMap 500 array which includes 528,173 SNPs [7]. To assess the association between 25(OH)D levels and individual SNPs, we first created an adjusted vitamin D level for each woman by regressing the plasma $25(\mathrm{OH}) \mathrm{D}$ concentration on age at blood draw, season (using a $\sin / \cos$ function [2]), body mass index, physical activity, laboratory batch, state of residence, and vitamin D intake from supplements and food sources, and taking the residuals of this regression. Linear regression was then performed by regressing the adjusted residual 25(OH)D levels on each SNP in the GWAS (coded by number of minor alleles). To address potential population stratification, models were adjusted for the top four principal components of variation, as previously described [10].

Further investigation of gene regions of interest was conducted through imputation of SNPs using the computationally efficient Hidden Markov Models implemented in MACH 1.0 [11] for SNPs categorized in the HapMap but not in the Illumina $500 \mathrm{~K}$ panel. The adjusted 25(OH)D was regressed on these SNPs using an expectation-substitution approach to account for uncertainty in imputed genotypes $[12,13]$.

SNP markers were considered for further study in relation to MS risk if they were either (1) significant at genome wide significance level $\left(p \leq 5 \times 10^{-8}\right)$ or (2) were suggestive of association at whole genome level (defined as $p \leq 1 \times 10^{-4}$ ) and a priori candidates based on a well described role in the vitamin $\mathrm{D}$ metabolic pathway. We considered as candidates the main enzymes involved in the metabolism of vitamin D (CYP27B1, CYP2R1, CYP27A1, $C Y P 24 A 1)$, the vitamin $\mathrm{D}$ binding protein $(G C / D B P)$, and the vitamin $\mathrm{D}$ receptor ( $V D R$ ).

\section{Association with MS in the IMSGC}

Study population-SNPs identified to be positive hits for predicting $25(\mathrm{OH}) \mathrm{D}$ using the criteria described above were examined in relation to MS risk in data from the participants in two MS genetics studies. First, we included participants in the International Multiple Sclerosis Genetics Consortium (IMSGC), [14] which includes MS cases from the United Kingdom and United States, and unrelated, healthy control subjects. We also analyzed an unpublished dataset of MS cases and controls enrolled in the Brigham and Women's Hospital (BWH) Genetics Collection, recruited at the Partners MS Center in Boston, Massachusetts. All MS cases met McDonald criteria [15]. Further details on demographic and clinical characteristics of participants in the BWH and IMSGC are described in a recent genome-wide meta-analysis for MS which utilized the same data [16]. For all individuals in the BWH Genetics Collection ( $n=860$ cases and 1,720 controls) and participants in the IMSGC in the US ( $n=342$ cases and 1,679 controls) and UK ( $n=453$ cases and 2,950 controls), we obtained direct genotype data (Affy $500 \mathrm{~K}$ ) as well as all imputed SNPs using the CEU phase 2 HapMap data [17] for a total study population of 1655 cases and 6349 controls. A subset of the IMSGC controls was also included as part of the recent ANZgene study which identified two novel MS susceptibility loci including a SNP upstream of CYP27B1 [18]. 
Methods-Main effects of SNPs identified from the GWAS of 25(OH)D were assessed via unconditional logistic regression models adjusting for gender and study. SNPs were coded as an additive or allelic model assessing the effect associated with an additional minor allele. Interactions with $H L A-D R 15$ were considered by including an interaction term in the logistic regression models which was the cross-product of the number of minor alleles for the 25(OH)D SNP and the number of minor alleles for HLA-DR15. The HLA-DR 15 genotype was determined by genotyping rs3135388, a SNP which is highly correlated $\left(r^{2}=\right.$ 0.97) with $H L A D R B 1 * 1501$ (HLA-DR15) [19].

Study specific estimates were pooled to determine a combined OR and 95\% CI using inverse variance weights [20]. Fixed effect model estimates were used as all tests of heterogeneity were non-significant at the $a=0.05$ level.

\section{Results GWAS of 25(OH)D}

In the GWAS of 25(OH)D levels including only the 872 women from the CGEMS study, no SNPs reached genome wide significance $\left(p<5 \times 10^{-8}\right)$. However, in the meta-analysis including these women as well as 3,629 men and women from four additional cohorts and an additional 4,378 replication samples from the NHS and HPFS, we identified genomewide significant associations with rs2282679 in $G C\left(p<1 \times 10^{-29}\right)$ and rs10741657 in CYP2R1 $\left(p<10^{-15}\right)$ [9]. No other markers met our selection criteria.

In our study population of the 872 CGEMS women, with an average $25(\mathrm{OH}) \mathrm{D}$ of $81.9 \mathrm{nmol} /$ 1, each additional ' $C$ allele of $G C$ rs 2282679 was associated with a $7.8 \mathrm{nmol}$ decrease in $25(\mathrm{OH}) \mathrm{D}$, and each additional ' $T$ ' allele of $G C$ rs7041 (a frequently studied nonsynonymous coding exon polymorphism in linkage disequilibrium with rs2282679) was associated with a $5.5 \mathrm{nmol} / \mathrm{dec}$ ease in $25(\mathrm{OH}) \mathrm{D}$. The finding of an association between the SNPs in $G C$, particularly our top hit rs2282679, and 25(OH)D levels is consistent with a recent publication in the PLCO Cancer Screening Trial [21]. In the CGEMS women, each additional ' $A$ ' allele of $C Y P 2 R 1 \mathrm{rs} 10741657$ was associated with a $5.3 \mathrm{nmol} / \mathrm{L}$ increase in 25(OH)D level. This SNP was of particular interest because of the previous report of its association with type 1 diabetes and 25(OH)D among diabetic patients [22].

\section{Established MS susceptibility loci and 25(OH)D levels}

We also investigated whether recently confirmed and newly identified MS susceptibility loci $[16,18]$ were associated with $25(\mathrm{OH}) \mathrm{D}$ levels in our population. Fifteen of 19 of these SNPs, or proxies with $r^{2}>0.8$, were identified in our data (HLA-DRB1, HLA-B, CD58, CLEC16A, IL7R, TNFRSF1A, CD6, CSCR4, PTGER2, MPHOSPH9, IL12A, OLIG3TNFAIP3, CYP27B1, CD40). None were associated with 25(OH)D levels (all $p>0.1$ ). Because of differences in genotyping platforms used, suitable proxies were not available for the SNPs in IL2RA, TNFRSF1A (rs4149584), IRF8, ZMIZ1 and RGS1.

\section{Association with risk of MS}

We tested the hypothesis that variants associated with increased plasma levels of $25(\mathrm{OH}) \mathrm{D}$ are inversely related to risk of MS in the combined BWH/IMSGC data. We also considered a SNP (rs703842) upstream of $C Y P 27 B 1$, recently identified in a GWAS of MS [18] and replicated in a more recent study [23]. $C Y P 27 B 1$ encodes the enzyme that catalyzes the conversion of $25(\mathrm{OH}) \mathrm{D}$ to its active form, $1,25(\mathrm{OH})_{2} \mathrm{D}$, and variations in $C Y P 27 B 1$ may thus contribute to tissue availability of vitamin $\mathrm{D}$. 
None of the $G C$ SNPs were associated with MS risk (OR $=0.96,95 \%$ CI: $0.88,1.05$; for rs2282679) and this effect did not vary by $H L A-D R 15$ genotype.

For $C Y P 2 R 1$ rs10741657, the association with MS risk was not significant, but the results were suggestive of an inverse association between the alleles that predict higher $25(\mathrm{OH}) \mathrm{D}$ levels and MS risk (Table 1). The interaction with $H L A-D R 15$ was not significant. However, in stratified analyses, the minor ' $A$ ' allele of rs 10741657 was suggestive of an association with a lower MS risk among $H L A-D R 15$ negative $(p=0.06)$, but not $H L A$ DR15 positive individuals (Table 1).

Similar to the previous report, which includes a sub-set of the controls used in the current study [18], rs703842, near $C Y P 27 B 1$ was significantly associated with risk of MS (Table 1). The interaction between this SNP and $H L A-D R 15$ was not significant, though the protective effect appeared to be stronger in $H L A-D R 15$ negative compared to $H L A-D R 15$ positive individuals (Table 1).

\section{Discussion}

To assess whether higher vitamin D levels may reduce the risk of MS, we identified genetic variants that predict high serum 25(OH)D levels, and then compared the risk of MS across the corresponding genotypes. Single nucleotide polymorphisms in $G C$, encoding the vitamin D binding protein, and $C Y P 2 R 1$, a key 25-hydroxylase that catalyzes the conversion of vitamin $\mathrm{D}$ to $25(\mathrm{OH}) \mathrm{D}$ [24], were identified as the strongest determinants of 25(OH)D levels [9]. No associations were found between $G C$ SNPs and MS risk, whereas there was evidence that the CYP2R1 genotype that results in the highest $25(\mathrm{OH}) \mathrm{D}$ levels was associated with a reduced risk of MS in $H L A-D R 15$ negative individuals, but not in $H L A$ $D R 15$ positive individuals. We also observed a significant association between $C Y P 27 B 1$ SNP rs703842, consistent with previous findings [18, 23], and MS risk, although this SNP was not associated with $25(\mathrm{OH}) \mathrm{D}$ levels, nor were any other MS susceptibility SNPs for which we had data available.

DBP transports vitamin D metabolites from the liver and kidneys to target tissues [25]. Greater than $85 \%$ of $25(\mathrm{OH}) \mathrm{D}$ and $1,25(\mathrm{OH})_{2} \mathrm{D}$ are bound to $\mathrm{DBP}$, with $25(\mathrm{OH}) \mathrm{D}$ showing a ten fold higher affinity [26]. We identified SNPs in $G C$ that were significantly associated with $25(\mathrm{OH}) \mathrm{D}$ levels. The strongest predictor of $25(\mathrm{OH}) \mathrm{D}$, rs2282679, was also previously identified in a study among 781 participants in the PLCO Cancer Screening trial [21] using a candidate gene/SNP approach and in a recent GWAS including our NHS CGEMS data [9]. For rs2282679, we observed a $20 \%$ reduction in $25(\mathrm{OH}) \mathrm{D}$ levels for those carrying the variant ' $A A$ ' compared to those with ' $C C$ genotype ( 70 vs. $87 \mathrm{nmol} / \mathrm{L}$ in NHS CGEMS women). Despite this notable difference in $25(\mathrm{OH}) \mathrm{D}$ levels, we did not observe an association between this or any of the $G C$ SNPs and risk of MS. Further stratification of risk estimates by $H L A-D R 15$ positivity did not reveal any interactions or suggestion of differential risk. The results of two previous studies of GC/DBPSNPs and MS risk, one including 236 Canadian sib-pairs and one among 107 Japanese cases and controls, also found no significant associations [27, 28].

The fact that MS risk was not increased among individuals carrying $G C$ variants associated with lower $25(\mathrm{OH}) \mathrm{D}$ levels is apparently inconsistent with the hypothesis that vitamin D reduces MS risk. It remains possible, however, that variations in $25(\mathrm{OH}) \mathrm{D}$ due to differences in DBP are poorly correlated with the availability of $25(\mathrm{OH}) \mathrm{D}$ to target tissues, perhaps because of concomitant changes in the DBP affinity for vitamin D metabolites. In particular, a polymorphism in the non-synonymous coding exon SNP (rs7041) that is in linkage disequilibrium with rs2282679, may reduce the DBP affinity for $1,25(\mathrm{OH})_{2} \mathrm{D}$ [29], 
and may thus result in relatively higher levels of free $1,25(\mathrm{OH})_{2} \mathrm{D}$ and maintained biological activity in spite of lower circulating $25(\mathrm{OH}) \mathrm{D}$ levels.

The other significant predictor of 25(OH)D levels, CYP2R1, rs10741657 is one of several SNPs in strong linkage disequilibrium found to be associated with circulating $25(\mathrm{OH}) \mathrm{D}$ levels [9]. We chose to study rs 10741657 because it was consistently associated with 25(OH)D levels in two previous studies, one among 133 individuals with type I diabetes in Germany [22], and one among German asthmatic families [30]. In our study of NHS CGEMS participants, the ' $A$ ' allele of rs 10741657 predicted a $7 \%$ increase in $25(\mathrm{OH}) \mathrm{D}$ levels relative to a mean of $81.9 \mathrm{nmol} / \mathrm{L}$ in our population. Based on the results of the only prospective study of $25(\mathrm{OH}) \mathrm{D}$ and MS risk [2], and applying a linear interpolation, a 4.5 $\mathrm{nmol} / \mathrm{L}$ increase in serum $25(\mathrm{OH}) \mathrm{D}$ (the increase associated with each additional ' $G$ ' allele of $C Y P 2 R 1$ rs10741657 in our GWAS) would predict a relative risk of MS of only 0.95 , which is the same relative risk of MS that we observed for an additive model. This consistency suggests that any observed association with $C Y P 2 R 1$ is likely mediated through the effect on $25(\mathrm{OH}) \mathrm{D}$ levels. The fact that our finding was not significant may be due to our relatively small sample size given the predicted modest effect on MS risk.

No polymorphisms in the CYP27B1 region were associated with $25(\mathrm{OH}) \mathrm{D}$ levels, consistent with some studies [21, 30], but not another in MS twins [31].

The relation between the variant $C Y P 2 R 1$ and $C Y P 27 B 1$ alleles and MS risk is possibly dependent on the presence of the $H L A-D R 15$ risk allele-among $H L A-D R 15$ negative individuals, the $C Y P 2 R 1$ ' $A$ ' and $C Y P 27 B 1$ ' $C$ ' alleles were associated with a 11 and $21 \%$ lower risk of MS, whereas among $H L A-D R 15$ positive individuals a weaker inverse association or no association was observed. An interaction between the effect of a polymorphism associated with circulating levels of $25(\mathrm{OH}) \mathrm{D}$ or bioavailability of vitamin $\mathrm{D}$ to target tissues and the $H L A-D R 15$ haplotype could be related to the recent findings of a highly conserved VDRE in the promoter region of the HLA DRB1*1501 haplotype. In ex vivo experiments, the conserved VDRE was found to be functional and bound VDR at a higher affinity than other VDREs. Stimulation with 1,25(OH)2D of cells transiently transfected with gene constructs including the consensus $H L A-D R 15$ sequence increased $H L A-D R B 1 * 1501$ expression 1.6 folds, while no change was seen for constructs bearing sequences specific to other DR haplotypes [5]. An increased expression of $H L A$ $D R B 1 * 1501$ could theoretically offset or dampen an otherwise beneficial effect of high levels of vitamin D.

There are certain limitations to our analysis. Though the number of subjects for the GWAS was relatively small, our results were consistent with the finding from the larger collaboration [9] and with a more recent large GWAS for 25(OH)D [32]. We also had only one measurement of $25(\mathrm{OH}) \mathrm{D}$ for each individual and, therefore, there is some misclassification of long term $25(\mathrm{OH}) \mathrm{D}$ status. However, in a subset of participants in the NHS, we have previously shown that a one time measure of $25(\mathrm{OH}) \mathrm{D}$ is a reasonable classification of exposure for 3 years (intraclass correlation over 3 year period $=0.7$ ) [33]. Finally, in the analyses relating genotype to MS risk, we could not account for UVB exposure and other environmental determinants of circulating 25(OH)D. Because genetic variations contribute only modestly to determine $25(\mathrm{OH}) \mathrm{D}$ levels, the expected associations between 25(OH)D-related SNPs and MS risk are modest, and could be obfuscated by variations in $25(\mathrm{OH}) \mathrm{D}$ due to environmental factors.

Overall, the results of this study provide only modest support to the hypothesis that genetically determined increases in serum $25(\mathrm{OH}) \mathrm{D}$ levels are associated with a reduced MS risk, and suggest that the possible protective effect of vitamin D may be restricted to 
individuals who do not carry the $H L A-D R 15 \mathrm{MS}$ risk allele. However, this finding requires replication and, because genotype was used as a proxy for actual $25(\mathrm{OH}) \mathrm{D}$ levels, the implicated effect needs to be confirmed in a study population where prospectively collected $25(\mathrm{OH}) \mathrm{D}$ levels can be directly measured.

\section{Acknowledgments}

The authors thank the International Multiple Sclerosis Genetics Consortium for the use of the genotype data for MS subjects. The work presented here is the sole content of the authors and does not necessarily represent the view of the National Institutes of Health. This work was funded by the National Institutes of Health/National Institute of Neurological Disorders and Stroke (R01 NS47467). Dr Simon was supported by a National Institute of Health/ National Research Service Award grant (T32 ES016645-01).

\section{References}

1. Munger KL, Zhang SM, O'Reilly E, Hernán MA, Olek MJ, Willett WC, Ascherio A. Vitamin D intake and incidence of multiple sclerosis. Neurology. 2004; 62:60-65. [PubMed: 14718698]

2. Munger KL, Levin LI, Hollis BW, Howard NS, Ascherio A. Serum 25-hydroxyvitamin D levels and risk of multiple sclerosis. J Am Med Assoc. 2006; 296:2832-2838.

3. Cantorna MT. Vitamin D and multiple sclerosis: an update. Nutr Rev. 2008; 66:S135-S138. [PubMed: 18844840]

4. Ascherio A, Munger KL. Environmental risk factors for multiple sclerosis. Part II: noninfectious factors. Ann Neurol. 2007; 61:504-513. [PubMed: 17492755]

5. Ramagopalan SV, Maugeri NJ, Handunnetthi L, Lincoln MR, Orton S, Dyment DA, DeLuca GC, Herrera BM, Chao MJ, Sadovnick AD, Ebers GC, Knight JC. Expression of the multiple sclerosisassociated MHC class II allele HLADrB1*1501 is regulated by vitamin D. PLoS Genet. 2009; 5:e1000369. [PubMed: 19197344]

6. Clayton D, McKeigue PM. Epidemiological methods for studying genes and environmental factors in complex diseases. Lancet. 2001; 358:1356-1360. [PubMed: 11684236]

7. Hunter DJ, Kraft P, Jacobs KB, Cox DG, Yeager M, Hankinson SE, Wacholder S, Wang Z, Welch R, Hutchinson A, Wang J, Yu K, Chatterjee N, Orr N, Willett WC, Colditz GA, Ziegler RG, Berg CD, Buys SS, McCarty CA, Feigelson HS, Calle EE, Thun MJ, Hayes RB, Tucker M, Gerhard DS, Fraumeni JF Jr, Hoover RN, Thomas G, Chanock SJ. A genome-wide association study identifies alleles in FGFR2 associated with risk of sporadic postmenopausal breast cancer. Nat Genet. 2007; 39:870-874. [PubMed: 17529973]

8. Bertone-Johnson ER, Chen WY, Holick MF, Hollis BW, Colditz GA, Willett WC, Hankinson SE. Plasma 25-hydroxyvitamin D and 1, 25-dihydroxyvitamin D and risk of breast cancer. Cancer Epidemiol Biomarkers Prev. 2005; 14:1991-1997. [PubMed: 16103450]

9. Ahn J, Stolzenberg-Solomon R, Simon K, McCullough M, Gallichio L, Jacobs E, Ascherio A, Helzlsouer K, Jacobs K, Li Q, Weinstein S, Purdue M, Virtamo J, Horst R, Wheeler W, Chanock S, Hunter D, Hayes R, Kraft P, Albanes D. Genome-wide association study of circulating vitamin D levels. Hum Mol Genet. 2010; 19:2739-2745. [PubMed: 20418485]

10. Han J, Kraft P, Nan H, Guo Q, Chen C, Qureshi A, Hankinson SE, Hu FB, Duffy DL, Zhao ZZ, Martin NG, Montgomery GW, Hayward NK, Thomas G, Hoover RN, Chanock S, Hunter DJ. A genome-wide association study identifies novel alleles associated with hair color and skin pigmentation. PLoS Genet. 2008; 4:e1000074. [PubMed: 18483556]

11. Huang L, Li Y, Singleton AB, Hardy JA, Abecasis G, Rosenberg NA, Scheet P. Genotypeimputation accuracy across worldwide human populations. Am J Hum Genet. 2009; 84:235-250. [PubMed: 19215730]

12. Kraft P, Cox DG, Paynter RA, Hunter D, De Vivo I. Accounting for haplotype uncertainty in matched association studies: a comparison of simple and flexible techniques. Genet Epidemiol. 2005; 28:261-272. [PubMed: 15637718]

13. Kraft P, Stram DO. Re: the use of inferred haplotypes in downstream analysis. Am J Hum Genet. 2007; 81:863-865. [PubMed: 17847013] 
14. International Multiple Sclerosis Genetics Consortium. Hafler DA, Compston A, Sawcer S, Lander ES, Daly MJ, De Jager PL, de Bakker PI, Gabriel SB, Mirel DB, Ivinson AJ, Pericak-Vance MA, Gregory SG, Rioux JD, McCauley JL, Haines JL, Barcellos LF, Cree B, Oksenberg JR, Hauser SL. Risk alleles for multiple sclerosis identified by a genome wide study. N Engl J Med. 2007; 357:851-862. [PubMed: 17660530]

15. McDonald WI, Compston A, Edan G, Goodkin D, Hartung HP, Lublin FD, McFarland HF, Paty DW, Polman CH, Reingold SC, Sandberg-Wollheim M, Sibley W, Thompson A, van den Noort S, Weinshenker BY, Wolinsky JS. Recommended diagnostic criteria for multiple sclerosis: guidelines from the International Panel on the diagnosis of multiple sclerosis. Ann Neurol. 2001; 50:121-127. [PubMed: 11456302]

16. De Jager PL, Jia X, Wang J, de Bakker PI, Ottoboni L, Aggarwal NT, Piccio L, Raychaudhuri S, Tran D, Aubin C, Briskin R, Romano S, Baranzini SE, McCauley JL, Pericak-Vance MA, Haines JL, Gibson RA, Naeglin Y, Uitdehaag B, Matthews PM, Kappos L, Polman C, McArdle WL, Strachan DP, Evans D, Cross AH, Daly MJ, Compston A, Sawcer SJ, Weiner HL, Hauser SL, Hafler DA, Oksenberg JR. Meta-analysis of genome scans and replication identify CD6, IRF8 and TNFRSF1A as new multiple sclerosis susceptibility loci. Nat Genet. 2009; 41:776-782. [PubMed: 19525953]

17. The International HapMap Consortium The International HapMap Project. Nature. 2003; 426:789796. [PubMed: 14685227]

18. The Australia New Zealand Multiple Sclerosis Genetics Consortium (ANZgene). Genome-wide association study identifies new multiple sclerosis susceptibility loci on chromosomes 12 and 20 . Nat Genet. 2009; 41:824-830. [PubMed: 19525955]

19. de Bakker PIW, McVean G, Sabeti PC, Miretti MM, Green T, Marchini J, Ke X, Monsuur AJ, Whittaker P, Delgado M, Morrison J, Richardson A, Walsh EC, Gao X, Galver L, Hart J, Hafler DA, Pericak-Vance M, Todd JA, Daly MJ, Trowsdale J, Wijmenga C, Vyse TJ, Beck S, Murray SS, Carrington M, Gregory S, Deloukas P, Rioux JD. A high-resolution HLA and SNP haplotype map for disease association studies in the extended human MHC. Nat Genet. 2006; 38:1166-1172. [PubMed: 16998491]

20. DerSimonian R, Laird N. Meta-analysis in clinical trials. Control Clin Trials. 1986; 7:177-188. [PubMed: 3802833]

21. Ahn J, Albanes D, Berndt SI, Peters U, Chatterjee N, Freedman ND, Abnet CC, Huang WY, Kibel AS, Crawford ED, Weinstein SJ, Chanock SJ, Schatzkin A, Hayes RB. Vitamin D-related genes, serum vitamin D concentrations and prostate cancer risk. Carcinogenesis. 2009; 30:769-776. [PubMed: 19255064]

22. Ramos-Lopez E, Bruck P, Jansen T, Herwig J, Badenhoop K. CYP2R1 (vitamin D 25hydroxylase) gene is associated with susceptibility to type 1 diabetes and vitamin D levels in Germans. Diabetes Metab Res Rev. 2007; 23:631-636. [PubMed: 17607662]

23. Sundqvist E, Baarnhielm M, Alfredsson L, Hillert J, Olsson T, Kockum I. Confirmation of association between multiple sclerosis and CYP27B1. Eur J Hum Genet. 2010; 18:1349-1352. [PubMed: 20648053]

24. Cheng JB, Levine MA, Bell NH, Mangelsdorf DJ, Russell DW. Genetic evidence that the human CYP2R1 enzyme is a key vitamin D 25-hydroxylase. Proc Natl Acad Sci USA. 2004; 101:77117715. [PubMed: 15128933]

25. Daiger SP, Schanfield MS, Cavalli-Sforza LL. Group-specific component (Gc) proteins bind vitamin D and 25-hydroxyvitamin D. Proc Natl Acad Sci USA. 1975; 72:2076-2080. [PubMed: 49052]

26. White P, Cooke N. The multifunctional properties and characteristics of vitamin D-binding protein. Trends Endocrinol Metab. 2000; 11:320-327. [PubMed: 10996527]

27. Steckley JL, Dyment DA, Sadovnick AD, Risch N, Hayes C, Ebers GC. Genetic analysis of vitamin D related genes in Canadian multiple sclerosis patients. Canadian Collaborative Study Group. Neurology. 2000; 54:729-732. [PubMed: 10680811]

28. Niino M, Kikuchi S, Fukazawa T, Yabe I, Tashiro K. No association of vitamin D-binding protein gene polymorphisms in Japanese patients with MS. J Neuroimmunol. 2002; 127:177-179. [PubMed: 12044990] 
29. Arnaud J, Constans J. Affinity differences for vitamin D metabolites associated with the genetic isoforms of the human serum carrier protein (DBP). Hum Genet. 1993; 92:183-188. [PubMed: 8370586]

30. Wjst M, Altmuller J, Faus-Kessler T, Braig C, Bahnweg M, Andre E. Asthma families show transmission disequilibrium of gene variants in the vitamin $\mathrm{D}$ metabolism and signalling pathway. Respir Res. 2006; 7:60. [PubMed: 16600026]

31. Orton S, Morris AP, Herrera BM, Ramagopalan SV, Lincoln MR, Chao MJ, Vieth R, Sadovnick $\mathrm{AD}$, Ebers GC. Evidence for genetic regulation of vitamin D status in twins with multiple sclerosis. Am J Clin Nutr. 2008; 88:441-447. [PubMed: 18689381]

32. Wang TJ, Zhang F, Richards JB, Kestenbaum B, van Meurs JB, Berry D, Kiel DP, Streeten EA, Ohlsson C, Koller DL, Peltonen L, Cooper JD, O'Reilly PF, Houston DK, Glazer NL, Vandenput L, Peacock M, Shi J, Rivadeneira F, McCarthy MI, Anneli P, de Boer IH, Mangino M, Kato B, Smyth DJ, Booth SL, Jacques PF, Burke GL, Goodarzi M, Cheung CL, Wolf M, Rice K, Goltzman D, Hidiroglou N, Ladouceur M, Wareham NJ, Hocking LJ, Hart D, Arden NK, Cooper C, Malik S, Fraser WD, Hartikainen AL, Zhai G, Macdonald HM, Forouhi NG, Loos RJ, Reid DM, Hakim A, Dennison E, Liu Y, Power C, Stevens HE, Jaana L, Vasan RS, Soranzo N, Bojunga J, Psaty BM, Lorentzon M, Foroud T, Harris TB, Hofman A, Jansson JO, Cauley JA, Uitterlinden AG, Gibson Q, Jarvelin MR, Karasik D, Siscovick DS, Econs MJ, Kritchevsky SB, Florez JC, Todd JA, Dupuis J, Hypponen E, Spector TD. Common genetic determinants of vitamin D insufficiency: a genome-wide association study. Lancet. 2010; 376:180-188. [PubMed: 20541252]

33. Tworoger SS, Lee IM, Buring JE, Rosner B, Hollis BW, Hankinson SE. Plasma 25hydroxyvitamin D and 1, 25-dihydroxyvitamin D and risk of incident ovarian cancer. Cancer Epidemiol Biomarkers Prev. 2007; 16:783-788. [PubMed: 17416771] 
Table 1

Odds ratios of multiple sclerosis according to $H L A-D R 15$ genotype

\begin{tabular}{|c|c|c|c|c|}
\hline & Genotype & Cases $(n=1,655)$ & Controls $(n=6,349)$ & OR $(95 \% \mathrm{CI})^{a}$ \\
\hline$H L A-D R 15$ & $\mathrm{CC} / \mathrm{CT} / \mathrm{TT}(\%)$ & $43 / 48 / 9$ & $72 / 25 / 2$ & $3.06(2.76,3.38)$ \\
\hline$G C$, rs 2282679 & CC/CA/AA $(\%)$ & $51 / 40 / 8$ & $51 / 40 / 9$ & $0.96(0.88,1.05)$ \\
\hline CYP2R1, rs 10741657 & GG/GA/AA $(\%)$ & $40 / 45 / 15$ & $37 / 48 / 15$ & $0.95(0.88,1.04)$ \\
\hline CYP27B1, rs 703582 & $\mathrm{TT} / \mathrm{TC} / \mathrm{CC}(\%)$ & $50 / 42 / 8$ & $46 / 44 / 10$ & $0.87(0.80,0.95)$ \\
\hline \multicolumn{5}{|c|}{ Distribution of $G C$ rs 2282679 genotypes in MS cases and controls } \\
\hline Among HLA-DR15- & CC/CA/AA (\%) & $52 / 40 / 8$ & $51 / 41 / 9$ & $0.91(0.80,1.04)$ \\
\hline Among $H L A-D R 15+$ & CC/CA/AA (\%) & $51 / 41 / 9$ & $52 / 39 / 9$ & $1.02(0.89,1.16)$ \\
\hline$P$ for interaction & & 0.10 & & \\
\hline \multicolumn{5}{|c|}{ Distribution of $C Y P 2 R 1$ rs 10741657 genotypes in MS cases and controls } \\
\hline Among HLA-DR15- & GG/GA/AA $(\%)$ & $42 / 42 / 15$ & $36 / 49 / 15$ & $0.89(0.79,1.01)$ \\
\hline Among $H L A-D R 15+$ & GG/GA/AA (\%) & $38 / 48 / 15$ & $38 / 47 / 14$ & $1.05(0.93,1.19)$ \\
\hline$P$ for interaction & & 0.06 & & \\
\hline \multicolumn{5}{|c|}{ Distribution of $C Y P 27 B 1$ rs703842 genotypes in MS cases and controls } \\
\hline Among $H L A-D R 15-$ & $\mathrm{TT} / \mathrm{TC} / \mathrm{CC}(\%)$ & $53 / 40 / 6$ & $46 / 44 / 10$ & $0.79(0.69,0.90)$ \\
\hline Among $H L A-D R 15+$ & $\mathrm{TT} / \mathrm{TC} / \mathrm{CC}(\%)$ & $47 / 43 / 9$ & $45 / 44 / 11$ & $0.91(0.80,1.04)$ \\
\hline$P$ for interaction & & 0.10 & & \\
\hline
\end{tabular}

Adjusted for gender and study

${ }^{a}$ OR for an additional minor allele 